\title{
$\nabla$ Effectiveness of Yogic Intervention in Non-Alcoholic Fatty Liver Disease: Case Series
}

\section{IJCRR}

Section: Healthcare

ISI Impact Factor

(2019-20): 1.628

IC Value (2019): 90.81

$\operatorname{SJIF}(2020)=7.893$

(c) (7) (8)

Copyright@IJCRR

\section{Panda Ashok Kumar ${ }^{1}$, Palei Deepti², Mohanty Rakesh Kumar ${ }^{3}$, Swain Dinesh Prasad Swain4, Prativa Shree ${ }^{5}$}

'Research Officer (Ayurveda), Central Ayurveda Research Institute for Hepatobiliary Disorders, Bhubaneswar, Odisha, India, ${ }^{2}$ Senior Research Fellow, Central Ayurveda Research Institute for Hepatobiliary Disorders, Bharatpur, Bhubaneswar-29, m/o AYUSH, Govt of India; ${ }^{3}$ Consultant Yoga Therapy, Utkal Hospital, Keojhar, Odisha, India; ${ }^{45}$ Assistant Professor, Department of Yogic Science, Sri Sri University, Cuttack, Odisha, India.

\section{ABSTRACT}

Background: Non-Alcoholic Fatty Liver Disease (NAFLD) is most prevalent and projected as the state of disease and associated with metabolic syndrome high treatment cost. Regular exercise especially 'Yoga' is a preferable and economical preventive and curative measure in the management of NAFLD because there are no licensed drugs available for NAFLD and people embracing a sedentary lifestyle. Transient elastography (TE)provides the Liver stiffness measurement (LSM) used here as a marker of fibrosis in these NAFLD cases.

Objectives: The objective of this case series was to evaluate the role of yoga in NAFLD patients without any medication.

Methods: Three NAFLD patients identified retrospectively who had been prescribed yogic intervention without any medication.

Result: This retrospective case series showed Kapalabhati Pranayama, Ardha matsyendrasana, Gomukhasana, Dhanurasana, Balasana and Dhyana (Meditation) are effective yogic interventions practised for 20 minutes in three NAFLD patients. This intervention can be corrected of blood sugar, blood lipids, elevated liver enzymes and liver fibrosis in studied three NAFLD patients

Conclusion: This preliminary case series showed yogic intervention can useful in NAFLD. More studies are recommended.

Key Words: NAFLD, Kapalabhati Pranayama, Ardha matsyendrasana, Gomukhasana, Dhanurasana

\section{INTRODUCTION}

Non Alcoholic Fatty Liver Diseases (NAFLD) represents a spectrum of diseases from simple steatosis to fibrosis and is thought to be present in up to $70 \%$ of people with type 2 diabetes and obesity. The prevalence of NAFLD is to be around $9-32 \%$ in the general Indian population, with a higher incidence amongst overweight/obese and diabetic/ pre-diabetic patients. ${ }^{1}$ NAFLD is projected as the state of disease and associated with a doubling health care cost, need for liver transplantation; including raised death risk from cardiovascular disease, hepatocellular cancer, and other noncancer causes like liver Cirrhosis. ${ }^{2}$ Ayurveda medication is excellent, but limited evidence. ${ }^{3}$ Regular exercise especially 'Yoga' is a preferable and economical preventive and curative measure in the management of NAFLD because there are no licensed drugs available for NAFLD and people embracing a sedentary lifestyle. ${ }^{4}$

Yoga and Ayurveda are interlinked and yoga is one of the Indian philosophies that mean for self-improvement by gaining full potential of one's body, mind and soul. Over ten years, Pranayama (breathing exercise), Asana (yogic posture), and dhyana (meditation) are very popular in clinical medicine for Non-pharmacological approaches in many non-communicable diseases. Yoga therapy has proven efficacy in obesity, ${ }^{5,6}$ prediabetic ${ }^{7}$ and can also correct liver function. ${ }^{8}$ Yoga therapy is beneficial in Alcoholic liver disease ${ }^{9}$ and Cirrhosis of the Liver ${ }^{10}$. The efficacy of Surya namaskar (sun salutation) on NAFLD is well studied with inconclusive result ${ }^{11}$. Surya namaskar (sun salutation) is quite difficult to practice, therefore the efficacy of other yogic practices like- Kapalabhati Pranayama, Ardha matsyendrasana, Gomukhasana, Dhanurasana, Balasanaand Dhyana (Meditation) in NAFLD is to be tested.

Kapalabhati Pranayama is the type of rapid breathing technique to maintain homeostasis and well being. It can correct the functions of abdominal organs, purify blood and tone the abdominal muscle. ${ }^{12,13}$ Ardha matsyendrasana (seated spinal twist)squeeze and twisting the intestines and liver, helpful in

\section{Corresponding Author:}

Ashok Kumar Panda, Central Ayurveda Research Institute for Hepatobiliary Disorders, Bhubaneswar, Odisha, India Phone: 7044981670; Email: akpanda_06@yahoo.co.in

ISSN: $2231-2196$ (Print)

Received: 20.01 .2021
ISSN: 0975-5241 (Online)

Revised: 05.02 .2021
Accepted: 12.04 .2021 
healing any damage caused by fibrosis, inflammation, and stress. It can correct the function of the Annavahasrotas (gastro-intestinal tract) and is thought to be an effective liver ${ }^{14}$. Dhanurasana (Bow pose) is a type of back bending posture to reduce belly fat and power to reverse the biological age and stimulate the abdominal organs. ${ }^{15}$ Gomukhasana (Cow face pose) is mentioned in Ghernda Samhita and Hatha Yoga pradipika, which can induce relaxation and alleviate fatigue. It stimulates the liver, pancreas and Kidney and prevents diabetics, low back pain. This pose can be practised for 30 seconds to one minute depending on the individual capacity for best therapeutic benefits and it can be increased gradually.$^{16}$ Balasana (Child'spose) is one of the counter postures of dhanurasana (Bow pose) and maintain quality of life. ${ }^{17}$ Dhyana is the uninterrupted connection between the mind and the object chosen for meditation. ${ }^{18}$

The objective of the study- The objective of this case series was to evaluate the role of yogic techniques in NAFLD patients without any medication.

\section{MATERIALS AND METHODS}

We retrospectively identified three NAFLD patients who had been prescribed yogic intervention without any medication. The patients between the ages of 30-50 years were included and patients taking any medication were excluded from the study.

A. Patient Information\& clinical finding- Three patients were diagnosed sonographically. Among three patients, two were male and one female. All three patients were non-vegetarian. All patients complained of anorexia, indigestion and distension of the abdomen for more than three months. All patients having central obesity, overweight and BMI is more than 27 (Table no-1). Their viral hepatitis screening was negative antinuclear antibody, smooth muscle antibody, $\alpha_{1}$-antitrypsin, ceruloplasmin, and thyroid-stimulating hormone levels were within normal limits. All patients had elevated blood sugar, triglyceride and slightly elevated liver enzymes (SGOT \& SGPT). The other liver enzymes and Platelet count were normal (Table no-2). All patients have elevated glucose levels.

B. Timeline- The Specific Yoga asana and pranayama were practised under the guidance of a Yoga expert. The assessment was taken after 30days and after the completion of 90 days of intervention.

C. Diagnostic assessment- The diagnosis of NAFLD requires evidence of hepatic steatosis by imaging or by histology. Ultrasound is very effective in diagnosis steatosis where more than $33 \%$ of hepatocytes are stenotic. Transient elastography (TE) provides the Liver stiffness measurement (LSM) using pulse-echo ultrasound as a surrogate marker of fibrosis. The Spe- cific Yoga asana and pranayama for 90 days under the guidance of a Yoga expert. The important parameters before the commencement of the Yoga exercises (baseline values) and after the Yoga therapy were recorded. ${ }^{15-18}$

D. Yogic intervention- All the subjects within the yogic techniques were taught Kapalbhati pranayama, Yogasana and dhyana. The duration of practice was for 20 minutes from 7 A.M. to 8 A.M. It was advised to keep bowel and bladder emptied before yogic practice. The duration of Kapalbhati pranayama was 9 minutes approximately, that of asanawas 9 minutes and dhyana 3 minutes approximately. Kapal bhatipranayama should is practised on an empty stomach. These studied patients were advised to sit comfortably with crossed leg position with straining of the back and hands should be rested on knees. Kapalavati is the exercise of contraction of the abdomen with forceful exhalation and inhalation. One stroke was completed with the completion of exhalation with inhalation. The patient begins with 30 strokes and ended with hundred eighty strokes. After completing such 30 strokes inhale and exhale deeply and take a rest-pause of about 30 seconds. The patients were advised to keep their bodies steady without any movements of the head, shoulder and legs. This kapalabhati can be done for nine minutes. Two sitting asana like Ardha matsyendrasana and Gomukhasana, two lie position of opposite body movement as Dhanurasana Balasana and Dhyana, at last, were practised with a standard protocol (Table 3)

E. Follow up and Result- The patient was followed up in 30days and 90days. The three patients have improved clinically and the radiological and biochemical parameters gradually developed during the period. After 30 days of treatment, their appetite appeared normal and got relieved abdominal discomfort, but no significant change in weight. The blood sugar and other parameter were slightly changed and significant change after three months of practice. The Ultrasound report of two patients became normal and change Midline stiff in fibro scan. There was a significant change in biochemical and radiological findings in all patients after three months(Table no-4)

\section{RESULT \& DISCUSSION}

This present case series is a retrospective evaluation of 90 days of yogic intervention in a special protocol of kapalabhati, two sitting asana, two lay down asana and dhya$n a$ in three NAFLD patients. After 30 days of treatment, their appetite appeared normal and got relieved abdominal discomfort, but no significant change in weight. The blood sugar and other parameter were slightly changed and significant change after three months of practice. The Ultrasound report of two patients became normal and 
significant change in Midline stiffness in the fibro scan report. This yogic intervention is a preliminary report of the correction of liver fibrosis and elevated liver enzymes in three NAFLD patients. Although earlier two case reports were suggested that yogic intervention can stabilise SGOT and SGPT. ${ }^{11}$ This yogic intervention also corrected metabolism for which blood sugar, total cholesterol and serum triglyceride reduced significantly. Similar studies were found that yogic interventions have decreased fasting plasma glucose, postprandial blood sugar, total cholesterol, triglycerides and reduce weight. Kaphalbhati pranayama and dhyana are correct metabolic functions and heals the mind by reducing stress and anxiety respectively. ${ }^{19-22}$ Kapalbhati Prayanam (Breathing exercise) is aimed at pushing (exhaling) out air from the stomach as if it is pumping out toxins/negativity from the body. In NAFLD, oxygenation and blood flow are prevented by scar liver tissues. The liver becomes unable to filter toxins and perform its other vital functions leading to cirrhosis, liver failure, liver cancer. By practising the said yoga protocol, the liver gets stimulated, thereby ensuring that oxygen and blood flow freely through it. Management of weight and stress is quite important while dealing with any chronic illness like liver disease. ${ }^{23}$

\section{CONCLUSION}

This preliminary retrospective study reveals that yogic intervention can correct blood sugar, blood lipids, elevated liver enzymes and liver fibrosis of NAFLD patients. It will attract more Clinical trials in a high sample size. These Nonpharmacological interventions have more priorities and the potential to improve future clinical trials in NAFLD. This study will provide a more informative guide to patients and practitioners regarding Yogic intervention and Fatty liver. Widespread dissemination of this study will optimise the usefulnessYogic intervention in Fatty liver diseases.

\section{ACKNOWLEDGEMENT}

The authors acknowledged DG, CCRAS, vice-chancellor and Dean of Sri Sri University and all participants of this study.

\section{Consent of patients: Obtained}

\section{Conflict of Interest: Nil}

No financial assistance was obtained from any sources.

\section{Author's contribution}

AKP and DP conceived the idea of this case study and plan the study design. RKM, DPS and PSS have finalised the yogic intervention and guided the patients. All authors are involved in the study and drafting of the manuscript, revising and providing final approval for publication.

\section{REFERENCES}

1. Benedict M, Zhang X. Non-alcoholic fatty liver disease: An expanded review. World J Hepatol. 2017;9(16):715-732.

2. Thomas G C, Mary R, Non Alcoholic liver disease 2020:The state of disease. Gatroenterology. 2020;158(7):1851-1864.

3. Panda A.K, Hazra J. PotalaKaturohinyadiKwatha In KaphajaYakritDalludara (Non-Alcoholic Fatty Liver Disease): A Case Study. Int J Ayurv Pharma Res. 2020;8(11):1-8.

4. Mishra AS, Sk R, Hs V, et al. Knowledge, Attitude, and Practice of Yoga in Rural and Urban India, KAPY 2017: A Nationwide Cluster Sample Survey. Medicines (Basel). 2020;7(2):8. Published 2020 Feb 5. doi:10.3390/medicines7020008

5. Gadham J, Sajja S, Rooha S, Effect of Yoga on obesity, hypertension and lipid prole Int J Res Med Sci. 2015 May;3(5):10611065

6. Bernstein AM. Yoga in the management of overweight and obesity. Am J Life Med. 8.1 (2014): 33-41.

7. Jyotsna VP. Prediabetes and type 2 diabetes mellitus: Evidence for the effect of yoga. Ind $J$ End Met.2014;18(6): 745.

8. Sharma K. Krishna E. A study on the Effect of Yoga Therapy on Liver functions. Eur Sci J.2014; 10:62-65.

9. Naveen GH, Nithin K, Selva KG, Management of Alcoholic Liver Disease by Naturopathy and Yoga Intervention: A Case Report. Int J Yoga Allied Sciences (ISSN: 2278 - 5159) 2014;3(2): 2014.

10. Reva. S, V. Kavitha, A. Mooventhan. Effect of Yoga and naturopathy on the liver, renal and cardiorespiratory functions of patients with hepatic cirrhosis with portal hypertension. J Compl Integ Med.(2017);15(4):1-6. DOI: https://doi.org/10.1515/jcim2017-0098

11. KayelarasiC.A. \&VenkateswaranST. Efficacy of Surya namaskara on NAFLD patients-A Interventional study, Dissertation of The Tamilnadu Dr MGR Medical University, Chennai. 20162019.

12. Dinkar RK. Effect of Kapalabhati Pranayama on body mass index and abdominal skinfold thickness. Indian Med Gaz. 2013;11:424-426.

13. Ansari RM. Kapalabhati pranayama: An answer to modernday polycystic ovarian syndrome and coexisting metabolic syndrome?. Int J Yoga. 2016;9(2):163-167. doi:10.4103/09736131.183705.

14. Nitin S M, Desai P, Role of Ardha-Matsyendrasana on the disease of Annavahasrotas in perspective of Sharira. Int Ayu Med J. 2016;3453-3460.

15. Jason S, Rana A, Yadav S.K An Anatomical Exploration of "Dhanurasana" Int J Trend Sci Res Devp. 2020;4(4):5-11. URL: https://www.ijtsrd.com/papers/ijtsrd30878.pdf

16. McCall, Marcy C. How might yoga work? An overview of potential underlying mechanisms. J Yog Phys Ther. 2013; 3(1): 1.

17. Joshi LN, Effect of selected yoga asana on quality of life of CLBP patents. Eur J Physical Educ Sport. 2017;3(1):105-113.

18. Telles S, Singh N, Gupta RK, Balkrishna A. A selective review of dharana and dhyana in healthy participants. J Ayurveda Integr Med. 2016;7(4):255-260. doi:10.1016/j.jaim.2016.09.004

19. Mondal S, Kundu B, Saha S. Yoga as a Therapeutic Intervention for the Management of Type 2 Diabetes Mellitus. Int $J$ Yoga. 2018;11(2):129-138. doi:10.4103/ijoy.IJOY_74_16

20. Seo DY. Yoga training improves metabolic parameters in obese boys. Kor J Phys Pharm. 16.3 (2012): 175-180. 
21. CAP RYT. A narrative review of yoga intervention clinical trials including weight-related outcomes. Alter Ther Health Med. 2013; 19(3): 32-35.
22. Mungal S, Bondade A, Effect of Sudarsana kriya yoga on lipid profile, Int J Curr Res Rev. 2013;5(19):49-55.

23. https://www.ourpositivestory.com/the-best-yoga-for-liver-cirrhosis-fatty-liver-and-hepatitis-a-b-c-d-e/

Table 1: Demographic data three NAFLD patients

\begin{tabular}{lllllccc} 
S.N & Age & Sex & Diet & Clinical symptoms & Height & Weight & BMI \\
1 & 44 & M & Non Veg & Distention of abdomen & $165 \mathrm{~cm}$ & 74 & 27.2 \\
2 & 32 & M & Non Veg & Anorexia, indigestion & 170 & 85 & 29.2 \\
3 & 40 & F & Non Veg & Indigestion, constipation & 158 & 66 & 27.2 \\
\hline
\end{tabular}

Table 2: Baseline biochemical and radiological parameters of three NAFLD patients

\begin{tabular}{lcccccccccc} 
S.N. & FBS & PPBS & HbAiC & TC & TG & SGOT & SGPT & USG & Fibro scan \\
1 & 140 & 198 & 7.1 & 140 & 267 & 60 & 49 & Mild fatty liver & 7.8 \\
2 & 176 & 220 & 7.8 & 220 & 380 & 64 & 52 & Moderate fatty & 10.9 \\
3 & 148 & 180 & 6.8 & 128 & 185 & 45 & 40 & Mild fatty liver & 6.2 \\
\hline
\end{tabular}

FBS- fasting blood sugar, PPBS- post prandial blood sugar, Tc-total cholesterol, TG-Triglyceride,

Table 3: Detailed yogic intervention in three NAFLD patients

\begin{tabular}{|c|c|c|c|c|}
\hline Yogic intervention & Execution time & Frequency & Recovery time & Total time \\
\hline Kapalabhatipranayam & $\begin{array}{l}30 \text { strokes per min } \\
\text { 1stoke in } 2 \text { min }\end{array}$ & 6 repeats & 3osrest in between & $9 \min$ \\
\hline Ardhamatsyendrasana & 2 times both side & 4 repeats & 30 rest in between & $2.5 \mathrm{~min}$ \\
\hline Gomukhasana & 2 times both side & 4 repeats & 30 rest in between & 2.5 \\
\hline Dhanurasana & I min in One time & - & & 1.5 \\
\hline Balasana & 1 min one type & - & -- & 1.5 \\
\hline Dhyana & $3 \min$ & - & - & $3 \mathrm{~min}$ \\
\hline TOTAL & & & & $20 \mathrm{~min}$ \\
\hline
\end{tabular}

Table 4: Biochemical and Radiological findings of three NAFLD patients

\begin{tabular}{lcccccc} 
Lab Parameter & \multicolumn{2}{c}{ Case Nor } & \multicolumn{2}{c}{ Case no-2 } & \multicolumn{2}{c}{ Case no-3 } \\
& After 30 days & After 9o days & After 30 days & After 9o days & After 30 days & After 9o days \\
BMI & 27.00 & 25.2 & 29.2 & 28.0 & 27.2 & 27.00 \\
FBS mg/dl & 126 & 108 & 162 & 103 & 118 & 86 \\
PPBS & 150 & 136 & 202 & 142 & 148 & 116 \\
TC & 140 & 134 & 226 & 158 & 128 & 130 \\
TG & 220 & 152 & 358 & 270 & 170 & 142 \\
SGOT & 62 & 42 & 65 & 45 & 38 & 38 \\
SGPT & 48 & 36 & 50 & 42 & 40 & 36 \\
USG & ---- & normal & ------ & mild & ----- & normal \\
Fibroscan & ------- & 6.00 & ------- & 8.4 & ----- & 6.00 \\
\hline
\end{tabular}

